\title{
De la utilidad de las pasiones del alma en la Pasión segun San Mateo
}

\author{
Idoia Solores Etxabe \\ idoiasolores@gmail.com \\ IES Antigua-luberri.
}

\section{Resumen}

En este trabajo analizamos la Pasión según San Mateo desde un ángulo emocional. La importancia del manejo de las emociones con el fin de persuadir al oyente es ya un clásico desde la Retórica de Aristóteles. Descartes al tratar las pasiones al final de su vida, vincula su dominio con el concepto de virtud. Esta unión de lo ético y emocional se revela fundamental para la Reforma protestante. De esta concepción ético-afectiva se inspira el compositor a la hora de interpretar musicalmente el texto evangélico y la recreación poética del mismo. El objetivo de la Pasión según San Mateo, dentro del ámbito religioso, sería conmover al oyente sumergiéndolo en el drama de la Pasión para así reforzar su fe cristiana. La capacidad de persuasión emocional trasciende, hoy en día, el marco religioso para el que fue creada esta Pasión, pudiendo contribuir a la edificación de una conciencia moral laica partiendo de un relato lineal (el evangelio) glosado con arias y coros que involucran al oyente (creyente o no) en el drama. En este artículo ponemos en paralelo las definiciones y descripciones que Descartes hace de las pasiones y la musicalización que realiza J.S.Bach de estas en la Pasión según San Mateo.

\section{Palabras Clave}

Pasión según San Mateo, Bach, Descartes, pasiones del alma, emociones, persuasión. 


\title{
Of the utility of the passion for souls in St. Matthew Passion
}

\begin{abstract}
In this work we analyze the St Matthew Passion from an emotional angle. The importance of managing emotions in order to persuade is already a classic since Aristotle's Rhetoric. Descartes also deals with passions at the end of his life, linking his mastery to the concept of virtue. This union of the ethical and emotional reveals itself fundamental for the Protestant Reformation. The composer is inspired by this ethical-affective conception when composing poetic comments to the evangelical text. The objective of the St Matthew Passion, within the ecclesiastical sphere, would be to move the listener by immersing him in the drama of the Passion in order to reinforce the Christian faith. The capacity for emotional persuasion transcends, today, the religious framework for which this Passion was created, being able to contribute to the building of a secular moral conscience starting from a linear account (the gospel) glossed with arias and choirs that involve the listener (believer or not) in the drama. In this article we parallel the definitions and descriptions that Descartes makes of the passions and the musicalization of these by J.S. Bach in the St Matthew Passion.
\end{abstract}

\section{Key Words}

Matthew Passion, Bach, Descartes, passions of the soul, emotions, persuasion.

\section{Introducción}

La Pasión según san Mateo (PSM en adelante) es un oratorio que representa los últimos momentos de la vida de Jesús, desde su entrada en Jerusalén hasta su crucifixión, pasando por la última cena y el arresto como grandes momentos. En este drama musical se ponen en juego diferentes pasiones humanas tales como la ira, la burla, el arrepentimiento, la piedad y la tristeza culminando todo ello con la purificación del alma. Toda esta variedad emocional asegura el interés del oyente para con la historia que se está narrando, permitiendo su vivencia afectiva.

Estas pasiones habían sido estudiadas por Descartes un siglo antes siguiendo la estela de los clásicos. En su tratado de Las Pasiones del Alma, publicado en 1649, el filósofo realiza un pormenorizado estudio de las emociones (consideradas pasiones puesto que son padecidas) y de sus efectos corporales.

La labor de Bach consiste en magnificar las pasiones emergentes en el texto de la PSM (escrito por Picander) por medio de sublimes arias y coros polifónicos 
que sumergen al oyente anímicamente en el drama suspendiendo la linealidad de la narración y abriendo un espacio-tiempo para la experiencia estética.

El hecho de que la fisiología mecánica de Descartes haya sido superada por la ciencia actual, no nos autoriza a negarle su genialidad y su utilidad para entender la manera de abordar las pasiones en aquel tiempo. ${ }^{1}$

Según explica Dietrich Bartel, Lutero alentó la combinación de un ethos músico-teológico donde la música actúa como una fuerza ética, influyendo en el individuo a través de su reflejo del Creador divino. "Las historias bíblicas que describen el poder de la música se agregaron a los mitos clásicos tradicionales, combinando así los valores musicales cristianos y grecorromanos."

La música en Alemania confluye a través de la Reforma protestante con la tradición retórica antigua poniendo en valor todos los recursos musicales para persuadir emocionalmente al oyente. Ya en tiempos de de J.S.Bach, el crítico musical Mattheson en su último libro Der vollkommene Capellmeister "proporciona algunas explicaciones teóricas de las emociones recurriendo a una tradición de la filosofía y la psicología del siglo XVII que tiene su origen en Les Passions de l'âme."3 (Hill 2008, p.400). ${ }^{4}$

En este trabajo que nos ocupa, enfocaremos las pasiones tal y como las describió Descartes casi 100 años antes de la PSM en su libro arriba reseñado, ob-

1. Pura Sanchez Zamorano en la introducción de su artículo sobre la Generosidad en las Pasiones del alma de Descartes, afirma: "El hecho de que la fisiología mecánica de Descartes haya sido superada no nos autoriza, sin embargo, a desvirtuar el Tratado; tampoco a negarle, a esa fisiología, su genialidad, pues basta releer las explicaciones cartesianas de los instintos, los reflejos condicionados, la memoria, el trauma infantil y asuntos similarmente complejos, $\mathrm{y}$ "considerar atentamente» la fecha de su descubrimiento o invención, para volvernos a sentir profundamente admirados." Sánchez Zamorano (2003).

2. "And through his emphasis on the importance of music as well as the spoken (and preached) Word, Luther stimulated the integration of the rhetorical and musical disciplines. And through his theological reinforcement of the traditional ethical view of music, Luther encouraged the combination of a musico-theological ethos with the concept of the affections based on the speculative science of the numerical proportions of the musical intervals." "Music thereby acts as an ethical force, influencing the individual through its reflection of the divine Creator" "Both terms, passio and affectus, were used by early Christian writers, including Augustine. Here the concept of the affections was expanded to include both constructive and destructive passions, including human virtues and sins. The ethical and healing power of music was promulgated in music treatises throughout the Middle Ages and into the Baroque era. Biblical stories describing music's power were added to the traditional classical myths, thereby blending Christian and Greco-Roman musical values". Bartel (1997, p. 9, pp. 16-17, p.31).

3. Las traducciones de los textos de Axmacher, Bartel, Butt, Marissen, Mattheson, Mersenne y Rorty han sido realizadas por la propia autora del artículo.

4. En esta misma línea se expresan los trabajos de G.J. Buelow (2001) ya en la segunda parte del siglo XX. 
servando cómo la música de J.S.Bach imita las descripciones fisiológicas descritas por el filósofo francés. ${ }^{5}$

Para tratar de explicar cómo la música provoca en el oyente ese torbellino emocional recurriremos a las figuras de la retórica musical compiladas por Dietrich Bartel (1997). Como plantea López-Cano (2020, p.394): “Todos estos referentes o convencionalismos, aunque siempre hipotéticos, son importantes porque nos brindan un asidero para la interpretación". Así, no es tan importante certificar que Bach utilizara estos recursos premeditadamente, sino el demostrar que estas figuras retóricas eran prácticas habituales y reconocidas por los teóricos de la retórica musical precursores y contemporáneos de J.S.Bach. También nos beneficiaremos de las descripciones fisiológico-musicales expuestas por Marin Mersenne (1636) en su obra Harmonie Universelle siguiendo la estela marcada por Descartes en su Compendio de música. ${ }^{6}$

Nuestro plan consiste en analizar diferentes momentos de la PSM, siguiendo su desarrollo dramático, a partir del arresto en Getsemaní, momento desencadenante del drama. Si para Descartes la superación de las pasiones (que nos tienen a su merced y nos hacen sufrir) se consigue con la victoria de la virtud purificadora (Art.148), el oratorio aquí estudiado tiende también a concluir su relato con la gran catarsis colectiva tras el magnicidio. Comenzamos el análisis del drama con la pasión de la ira desatada por el apresamiento de Jesús.

\section{La ira}

El drama de la Pasión propiamente dicho comienza cuando arrestan a Jesús (traicionado por Judas) en medio de la noche. Los discípulos se enojan e intentan defenderle. Es un acto de injusticia y de felonía que por supuesto provoca la ira entre sus allegados. En el Art. 65, explica Descartes que "el mal hecho por otros, no siendo contra nosotros mismos, nos produce sólo indignación; y cuando es contra nosotros, nos mueve también a la ira"”.

El texto del evangelista Mateo traducido por Lutero dice:

\footnotetext{
5. No pretendemos sugerir en este trabajo que J.S.Bach hubiese leído a Descartes, puesto que no existe evidencia alguna de ello, simplemente deseamos establecer un paralelismo entre la descripción cartesiana de las pasiones y la manera en que esas pasiones son representadas musicalmente en la PSM por el músico.

6. El Compendio de música es la primera obra de Descartes escrita en latín en 1618. En ella introduce la noción de consonancia/disonancia producida por los intervalos armónicos y su relación con el placer sensorial.

7. Para Aristóteles la ira se produce también cuando la ofensa es dirigida contra los que nos son próximos, y se traduce siempre en un apetito de venganza. Aristóteles (1990, p. 312).
} 


\begin{tabular}{cc}
\hline Texto & Traducción \\
\hline Evangelist: & Evangelista: \\
$\begin{array}{c}\text { Und siehe, einer aus denen, die mit Jesu } \\
\text { waren, reckete die Hand aus und schlug des } \\
\text { Hohenpriesters Knecht und hieb inm ein } \\
\text { Ohr ab. }\end{array}$ & $\begin{array}{c}\text { Y he aquí que uno de lo que estaban con Jesús } \\
\text { sacó la espada y golpeó a un siervo del sumo } \\
\text { sacerdote y le cortó una oreja. }\end{array}$ \\
\hline
\end{tabular}

Tabla 1. Texto del evangelista en la PSM de J. S. Bach.

La respuesta furibunda del discípulo cristiano es glosada poéticamente por el libretista (Picander)con truenos, relámpagos y abismos de infierno.

\begin{tabular}{|c|c|}
\hline Texto & Traducción \\
\hline $\begin{array}{l}\text { Sind Blitze, sind Donner in Wolken verschwun- } \\
\quad \text { den? } \\
\text { Eröffne den feurigen Abgrund, o Hölle, } \\
\text { Zertrümmre, verderbe, verschlinge, zerschelle } \\
\text { Mit plötzlicher Wut } \\
\text { Den falschen Verräter, das mördrische Blut! }\end{array}$ & $\begin{array}{c}\text { ¿Relámpagos y rayos se acabaron en las } \\
\text { nubes? } \\
\text { ¡Abre tu ígneo abismo, oh infierno, } \\
\text { rompe, destruye, devora y estrella } \\
\text { con súbita furia } \\
\text { al falsario traidor y su sangre criminal! }\end{array}$ \\
\hline
\end{tabular}

Tabla 2. Dos coros $[s, c, t, b] n^{\circ} 27 b$ : Flautos traversos I/II, oboes I/II, violines I/II, viola, órgano continuo.

La reacción física de la ira es explicada por Descartes en el Art.199 de la siguiente manera:

“... El deseo (de venganza) unido al amor hacia uno mismo es lo que da a la ira toda la agitación de la sangre que pueden producir el valor y la intrepidez; y, en el odio, es principalmente la sangre biliosa procedente del bazo y de las venillas del hígado la que recibe esta agitación y entra en el corazón, donde, por su abundancia y por la naturaleza de la bilis mezclada a ella, produce un calor más áspero y más ardiente que el que puede ser producido por el amor o por la alegría (1649, p.35)"

La música de J. S. Bach juega con sus propios elementos para escenificar esta agitación interna, emulando los movimientos sanguíneos descritos por Descartes. La primera parte de este coro $\mathrm{n}^{\circ} 27$ como reacción al apresamiento de Jesús transcurre de manera plácida en un andante con compás de 4/4 para transformarse en el compás $n^{\circ} 65$ en un movimiento Vivace con un compás acelerado de 3/8. Aparecen los rayos. El bajo continuo arranca su ostinato en el compás n. ${ }^{\circ} 68$ con su constante movimiento semicircular en semicorcheas.

Bach echa mano de la imagen tormentosa que provee el texto para describir 
una furia desatada de la naturaleza, imagen metaforizada de la rabia que acompaña al sentimiento de indignación ante una injusticia. Para ello el músico pone en marcha los dos coros orquestales. Las voces cantan persiguiéndose unas a otras en un movimiento fugado con dos coros que invocan rayos y truenos. Estas voces entran escalonadamente en los dos coros al unísono, empezando por la más grave y terminando con la más aguda. Estas entradas están espaciadas por cuatro compases, lo que transmite una sensación de aglomeración in crescendo de personas que gritan con rabia una y otra vez la misma pregunta. Llegados al compás $\mathrm{n}^{\circ}$ 85 la tensión crece, irrumpen los acordes en stacatto mientras siguen repitiendo obsesivamente el mismo verso: Sind Blitze, sind Donner in Wolken verscbwunden? (¿Relámpagos y rayos se acabaron en las nubes?). Es decir, se interrogan indignados si toda la rabia acumulada va a desaparecer en las nubes. Una pregunta retórica que se responderá con una petición expresa de castigo apocalíptico para el traidor.

Tras la pregunta se produce un silencio absoluto de un compás que permite acometer un cambio de textura como si de otro movimiento se tratara. A esta interrupción se la conoce retóricamente con el nombre de aposiopesis y produce evidentemente una cesura significativa entre la pregunta y la respuesta. Bartel (1997) nos explica que esta figura se define como "una pausa general en todas las voces" (p. 203). El término apo significa en griego separar y siopesis silencio. Esta figura está relacionada con la abruptio. "Sin embargo. mientras que la abruptio denota la ruptura repentina de un pasaje musical, la aposiopesis se refiere a un uso intencional y expresivo del silencio en una composición. (Bartel 1997, p.203)" Un poco más adelante Bartel nos informa que "la aposiopesis se encuentra con frecuencia en composiciones cuyos textos tratan sobre la muerte o la eternidad. En tales casos, es la aposiopesis más que la abruptio la que se emplea habitualmente, expresando infinito o nada" (Bartel 1997, p.203). ${ }^{8}$

Tras la aposiopesis se abre un nuevo espacio temporal en el que se prescinde de la imitación contrapuntística del pasaje anterior para decantarse por el canto homofónico, lo que potencia la comprensibilidad del texto. Este recurso de inclusión de un pasaje homofónico en un contexto imitativo está registrado retóricamente como noema. Según Bartel,

"Burmeister declara explícitamente que el noema sólo se puede reconocer en el

8. Most authors define aposiopesis as a general pause, affecting all the voices of a composition. As the literal meaning of the term suggests (from apo. away. from; siopesis. silence). aposiopesis signifies a certain silence in a composition. This figure is related to the abruptio, a point which Spiess also emphasizes. However. while the abruptio denotes the sudden breaking off of a musical passage, the aposiopesis is refers to an intentional and expressive use of silence in a composition. Furthennore, the abruptio's break is normally described as sudden and unexpected, a characteristic not necessarily associated with the aposiopesis... The aposiopesis is frequently encountered in compositions whose texts deal with death or eternity.' In such cases it is the aposiopesis rather than the abruptio which is usually employed, expressing infinity or nothingness. (Bartel 1997, p.203) 
contexto de la composición. No puede referirse a un pasaje homofónico per se, sino más bien sólo a tal pasaje dentro de un contexto contrapuntístico, la sección homofónica contrasta con la textura circundante, prestándole al texto asociado mayor énfasis y significado"' (Bartel 1997, p.340).

Esta nueva sección homofónica irrumpe con el texto Eröffne den feurigen $A b$ grund, o Hölle (Abre tu ígneo abismo, oh infierno) en el coro I, que será imitado a una distancia de 4 compases por el coro II. Las cuerdas apuntalan el horror con sus acordes en stacatto. La palabra Abgrund (abismo) es subrayada por una abrupta caída de todas las voces especialmente de la soprano con un salto descendente de $7 \mathrm{~m}$ y el bajo que se desploma una octava, el infierno Hölle se presenta con una nota re\# (la sensible de Mi M) mantenida durante más de tres compases con el apoyo de un acorde de 7 dominante. El bajo continua con su ostinato, repitiendo algunos compases hasta cuatro veces de manera idéntica.

Es el mismo texto el que establece la correlación entre la tormenta, la destrucción y la rabia: Zertrümmre, verderbe, verschlinge, zerschelle / Mit plötzlicher Wut (rompe, destruye, devora y estrella / con súbita furia). El último verso Den falschen Verräter, das mördrische Blut! (jal falsario traidor y su sangre criminal!) es cantado homofónicamente por los dos coros simultáneamente creando una armonización a ocho voces. Toda la ira se centra ahora en el traidor.

Para ahondar más en el mecanismo musical de mímesis de la cólera puede consultarse el artículo: "Reflexiones en torno a la semanticidad musical" (Solores 2020).

\section{La burla}

Tras el violento episodio emulando toda la ira provocada por la injusticia, el drama sigue adelante con su narración progresiva y asistimos con estupor a unos episodios repulsivos. La multitud ${ }^{10}$ lejos de apiadarse del reo, se dedica a burlarse de sus heridas y a golpearlo mientras se le dirigen palabras sarcásticas.

\footnotetext{
9. Burmeister explicitly states that the noema can only be recognized in the context of the composition. It does not refer to a homophonic passage per se but rather only to such a passage within a contrapuntal context.The homophonic section stands in contrast to the surrounding texture, thereby lending it and the associated text greater emphasis and significance. (Bartel idem, p. 340)

10. Michel Marissen sobre la palabra "multitud" expone que cualquiera que sea el propósito en el Evangelio de Mateo para diferenciar las palabras ocblos y laos, esa idea se pierde por completo en la versión del evangelio de Lutero, puesto que el reformador tradujo ambos términos como das Volk. Así, mientras que en Mateo el laos podría ser entendido como el pueblo judío y el ocbloi como una multitud compuesta en su mayoría por judíos, pero también con algunos o incluso muchos gentiles, en Lutero uno se encuentra sólo con judíos. Ahora bien, se podría objetar que en la lengua vernácula de los días de Lutero, la palabra das Volk cubría un campo semántico muy amplio que incluía varios términos del Nuevo Testamento griego. Al traducir ambos ochlos y laos como das Volk, Luther simplemente estaba
} 


\begin{tabular}{cc}
\hline Texto & Traducción \\
\hline Evangelist: & Evangelista: \\
$\begin{array}{c}\text { Da speieten sie aus in sein Angesicht und } \\
\text { schlugen ihn mit Fäusten. Etliche aber schlu- } \\
\text { gen inn ins Angesicht und sprachen: }\end{array}$ & $\begin{array}{c}\text { Entonces lo escupieron en la cara y lo golpea- } \\
\text { ron con los puños. Y algunos lo golpeaban en } \\
\text { la cara, y decían: }\end{array}$ \\
$\begin{array}{c}\text { Weissage uns, Christe, wer ist's, der dich } \\
\text { schlug? }\end{array}$ & $\begin{array}{c}\text { Profetízanos, Cristo, ¿quién es el que te ha } \\
\text { golpeado? }\end{array}$ \\
\hline
\end{tabular}

Tabla 3. Recitativo [Tenor] $n^{\circ} 36 c$ : órgano y continuo. Coros [s, c, t, b] $n^{\circ} 36 d$ : flautos traversos I/II, oboes I/II, violines I/II, viola, órgano y continuo.

Este comportamiento es expuesto por Descartes en el Art. 178:

"La irrisión o burla es una especie de alegría mezclada con odio, que se produce al ver algún pequeño mal en una persona a la que se cree digna de sufrirlo: se siente odio por ese mal, se siente alegría de verlo en quien lo merece; y cuando esto ocurre inopinadamente, la sorpresa de la admiración origina la risa, como dije al explicar la naturaleza de la risa. Pero ese mal debe ser pequeño; pues si es grande, no se puede creer que el que lo padece lo merece, a no ser que se tenga una mala índole o que se odie mucho a la persona en cuestión (1649, p.32);" 11

Para representar la burla J.S.Bach pone en marcha un coro de turba polifónico. Los coros de turba aparecen en la Pasión para dotar de mayor realismo al relato, representando el vocerío de la muchedumbre o de grupos de personas. El texto de estos coros pertenece a la narración evangélica de Mateo y para mostrar el barullo vocal estas agrupaciones efectúan un juego polifónico de voces que se superponen, con acompañamiento instrumental polifónico. Suelen ser apelaciones directas a Jesús y son momentos de gran dramatismo. Aquí el tono utilizado es claramente de burla, de provocación y de vejación de la figura de Jesucristo. ${ }^{12}$

Platen (2000) califica este pasaje (36 d) de coro burlón. En él se establece una alternancia antifonal entre dos coros que ilustra vivamente el ataque verbal desde dos lados. Al final del movimiento con la agitada síncopa de las voces de soprano, se desarrolla un ritmo tipo hoquetus en el que ambos coros alternan sus tiempos con una precisión casi cruel.

trabajando con las limitaciones de las herramientas lingüísticas disponibles. Marissen (2016, p.163)

11. Aristóteles (1990, p.314) habla de la vejación como una especie de desprecio hacia aquello que juzgamos carece de valor y que sabemos que no puede hacernos daño. Es pues una actitud cobarde y malintencionada.

12. Según nos hace saber Freud (1982, p.55) en El malestar en la cultura, la necesidad de buscar un chivo expiatorio para descargar todas las pulsiones agresivas derivadas de la frustración podría explicar el comportamiento ruin de todos aquellos que ven el martirio de un ser extraño como motivo de diversión. 
Este pasaje toma la forma de Fortspinnung. Se trata de una amplificación sición del tema a partir de una célula primitiva de tres corcheas en la palabra weissage ("profetízanos"), que es desarrollada a lo largo de 4 compases con juegos polifónicos de semicorcheas en las voces inferiores mientras las sopranos se imitan realizando un salto ascendente de sexta (la corchea en anacrusa- fa blanca) en el coro II que es respondido con un salto ascendente de cuarta en el coro I (la corchea en anacrusa- re blanca) respetando el mismo motivo rítmico. Este comportamiento marca una clara diferenciación entre el canto de las sopranos y el de las demás voces. Las palabras Christe, wer ist's, der dich schlug? ("Cristo, ¿quién es el que te ha golpeado?”). provocan una desaceleración del movimiento con parejas de corcheas sincopadas que en el último compás se acompasan rompiendo la alternancia para cerrar el pasaje con una cláusula final que deja oír claramente la pregunta sarcástica der dich schlug? (“¿quién te golpeó?”). Podríamos aquí hablar de nuevo de noema por la contraposición del estilo homofónico con el polifónico precedente. Estas últimas palabras sirven de nexo con el coral inmediatamente posterior que comienza con la pregunta:¿quién te ha golpeado así?

\section{La piedad, la compasión}

Frente al escarnio, la comunidad creyente reacciona cantando conjuntamente un coral en el que se muestra todo su apoyo afectivo al inocente, injusta y cruelmente apaleado. La narración aquí se detiene conectando al oyente con su interior a modo de oración y al mismo tiempo con su comunidad religiosa. El oyente no está solo en su abatimiento, es un sentimiento compartido, lo que siempre resulta reconfortante.

\begin{tabular}{cc}
\hline Texto & Traducción \\
\hline Wer hat dich so geschlagen, & ¿Quién así te ha golpeado, \\
Mein Heil, und dich mit Plagen & Salvador mío, y con tormentos \\
So übel zugericht'? & tan mal te ha juzgado? \\
Du bist ja nicht ein Sünder & Tú no eres un pecador, \\
Wie wir und unsre Kinder; & como nosotros y nuestros hijos; \\
Von Missetaten weißt du nicht. & de delitos nada sabes. \\
\hline
\end{tabular}

Tabla 4. Coral $[s, c, t, b] n^{\circ} 37$ : flautos traversos I/II, oboe I/II y violín I con sopranos, violín II con contraltos, viola con tenores, órgano, y continuo.

Descartes define la piedad en el Art. 185 como:

"una especie de tristeza entreverada de amor o de buena voluntad hacia las personas a quienes vemos sufrir algún mal del que no los creemos merecedores. Es, 
pues, contraria a la envidia por razón de su objeto, y a la burla porque los considera de otro modo" (1649, p.33).

El oyente protestante es aquí parte activa en la escucha, uniéndose a la comunidad mediante el canto, con una oración coral que le sirve de bálsamo apaciguador para soportar toda la descarga emocional del momento. Por medio de este coral $n^{\circ} 37$, la comunidad protestante que asiste al drama se apiada del destino de esa víctima a quien vemos sufrir un mal que no merece.

La letra de los corales de la PSM no es autoría de Picander, sino que al igual que su música pertenece al acervo de la tradición protestante. Bach es el encargado de armonizarlos homofónicamente para poder ser cantados por la comunidad. Platen (2000) piensa que fue el mismo Bach quien se encargó de escoger estas piezas corales y quien decidió su lugar de inserción en el drama. El texto del coral que nos ocupa está extraído de la segunda estrofa del himno O Welt, sieh hier dein Leben ("Oh mundo, mira aquí tu existir") escrito en 1647 por Paul Gerhardt"13.

Estos corales están perfectamente imbricados en la narrativa, siendo su texto como un comentario a lo recientemente acaecido. Así el comienzo del coral Wer hat dich so geschlagen ("quién así te ha golpeado") retoma las últimas palabras del coro de turba narrativo inmediatamente anterior wer ist's, der dich schlug? ("¿quién es el que te ha golpeado?") sin cesura y manteniendo el mismo compás y la misma tonalidad de la cadencia final ( $\mathrm{Fa} \mathrm{M}$ ) del movimiento precedente. Se podría hablar de anadiplosis, una figura retórica ya compilada por Susenbrotus en el siglo XVI y ratificada en los mismos términos por Gottsched (Redekunst) o Walther (Lexicon) contemporáneos de J.S. Bach. La anadiplosis o reduplicatio ocurre según Susenbrotus "cuando la última palabra de un pasaje anterior se repite al comienzo del siguiente o cuando construimos una apertura de un pasaje posterior a partir del anterior ya cerrado."14

En cuanto a la temática Axmacher (1984) clasifica los corales de esta PSM en tres grandes grupos: el primero engloba a aquellos cuyo texto ofrece una reflexión contemplativa sobre el sufrimiento de Cristo, empatizando con su sufrimiento; el segundo trata del sentido de salvación de la Pasión y el arrepentimiento; y el tercero se ocupa de la paciencia cristiana, sufrimiento y muerte del cristiano ${ }^{15}$.

13. Paul Gerhardt (1607-1676) es el escritor alemán de himnos protestantes más importante de su época. Seguidor de Lutero sufrió las penurias de la guerra de los 30 años que a decir de Schweitzer en su libro sobre J.S.Bach es una de las fuentes de inspiración más fecundas de este tipo de textos. Schweitzer (2000, p.10).

14. Susenbrotus (Epitome p.53) The anadiplosis or reduplicatio occurs when the last word of a preceding passage is repeated at the beginning of the following one or when we construct a subsequent opening out of the preceding (Bartel 1997, p.181)

15. 1) Kontemplative Betrachtung des leidenden Christus, Anteilnahme an seinem Leiden. 2) Heilsbedeutung der Passion und Buße. 3) Christliche Geduld, Leiden und Sterben des Christen. Axmacher 
El coral aquí tratado ( $\left.\mathrm{n}^{\circ} 37\right)$ está incluido en el primer grupo, mientras que el n. ${ }^{\circ} 10$-Ich bin's, ich sollte büßen ("Soy yo el que debería expiar")- que utiliza la misma melodía se inserta en el segundo. Esta circunstancia evidencia que lo que prima en la clasificación de Axmacher es el texto y no la melodía.

La melodía es una parodia ${ }^{16}$ de la canción popular alemana Innsbruck, ich muss dich lassen ("Debo dejarte") compuesta en 1490 por el compositor flamenco Heinrich Isaac (1450-1517).

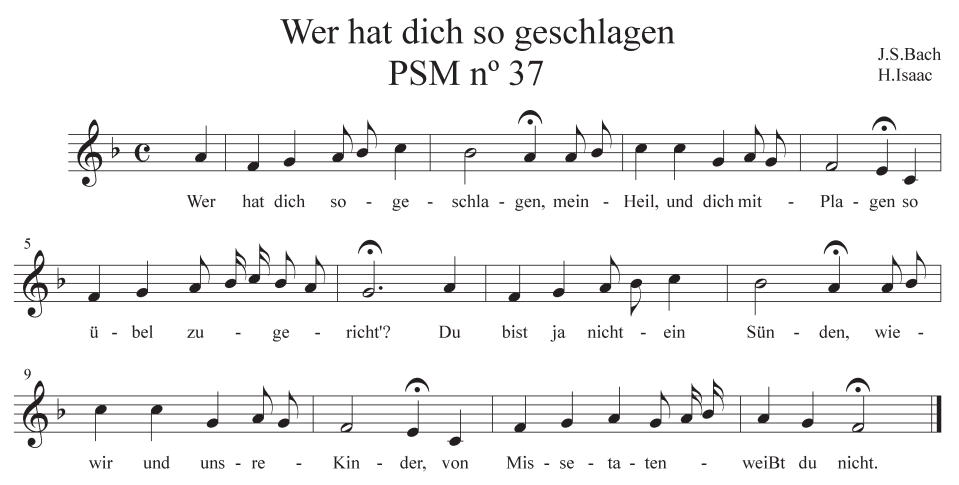

Figura 1. Coral no 37 de la PSM.

Lo que resulta interesante para nuestro estudio es que las melodías de estas piezas corales suelen ser pausadas, sin estridencias armónicas y se conducen por movimiento conjunto, lo que contribuye a crear una calma desde la cual se hace posible el sentimiento de la compasión ${ }^{17}$. Bach adorna las palabras zugericht ("juzgado") y missetaten ("delitos") con un pequeño melisma acentuando así el sinsentido de la injusticia del falso juicio y la ausencia de delito. El hecho de ser un canto conocido por la congregación, que lo entona al unísono, ayuda a reafirmar el vínculo religioso comunitario e involucra al oyente en el drama de una manera empática como contraposición al movimiento sarcástico anterior.

Dice Axmacher (1984) que esta conexión entre la piedad y la muerte incorpora

(1984, p.198,199).

16. En este contexto el término "parodia" no tiene ninguna connotación burlesca u humorística, tan sólo alude a la mera sustitución del texto de una obra por otro, por una razón práctica de economía de tiempo y también porque al tratarse de una melodía tradicional todos los congregados en el oficio son capaces de reconocer y de cantar comunitariamente, conectándose directamente con su imaginario cultural.

17. Mersenne vincula los aires tristes a la compasión. Ver nota no 20 . 
un aspecto ético y es en este punto "donde podría encontrar su punto de partida la consideración puramente emocional y humana de la Pasión” (p.202). ${ }^{18}$

En el art. 188, Descartes retrata a aquellos que no sienten piedad de la siguiente manera:

"Pero sólo son insensibles a la piedad los espíritus malévolos y envidiosos que odian naturalmente a todos los hombres, o bien los que son tan brutales, tan cegados por la buena suerte o desesperados por la mala, que no piensan que pueda ocurrirles ningún mal” (1649, p.34).

Volvemos aquí al tema de la cobardía y la malevolencia, una constante a lo largo de todo el drama.

\section{El miedo}

Pedro es reconocido como discípulo del arrestado. Es poco a poco acorralado y presa del pánico niega hasta tres veces su vínculo con el maestro, rompiendo así la promesa de fidelidad y derrumbándose al oír el canto del gallo. Esta es la señal predicha por Jesús en el monte de los olivos. Este cacareo le recuerda su falta y reprueba su conducta, primero por negar al maestro y segundo por faltar a la promesa dada.

\begin{tabular}{|c|c|}
\hline Texto & Traducción \\
\hline $\begin{array}{l}\text { Wahrlich, du bist auch einer von denen; denn } \\
\text { deine Sprache verrät dich. }\end{array}$ & $\begin{array}{l}\text { Ciertamente tú también eres uno de ellos, pues } \\
\text { tu acento te delata. }\end{array}$ \\
\hline $\begin{array}{l}\text { Evangelist: } \\
\text { Da hub er an, sich zu verfluchen und zu } \\
\text { schwören: }\end{array}$ & $\begin{array}{l}\text { Evangelista: } \\
\text { Entonces comenzó a maldecir y a jurar: }\end{array}$ \\
\hline $\begin{array}{l}\text { Petrus: } \\
\text { Ich kenne des Menschen nicht. }\end{array}$ & $\begin{array}{c}\text { Pedro: } \\
\text { ¡No conozco a ese hombre! }\end{array}$ \\
\hline $\begin{array}{l}\text { Evangelist: } \\
\text { Und alsbald krähete der Hahn. Da dachte } \\
\text { Petrus an die Worte Jesu, da er zu inm sagte: } \\
\text { Ehe der Hahn krähen wird, wirst du mich drei- } \\
\text { mal verleugnen. Und ging heraus und weinete } \\
\text { bitterlich. }\end{array}$ & $\begin{array}{c}\text { Evangelista: } \\
\text { Y al punto cantó el gallo. Entonces recordó } \\
\text { Pedro las palabras de Jesús, cuando le dijo: } \\
\text { Antes de que el gallo cante, me negarás tres } \\
\text { veces, y salió fuera y lloró amargamente. }\end{array}$ \\
\hline
\end{tabular}

Tabla 5. Coro $[s, c, t, b] n^{\circ} 38 b$ : flautos traversos I/II, oboe I, oboe d'amore II, violines I/II, viola, órgano y continuo. Recitativo [tenor y bajo] (Evangelista y Pedro), 38c: órgano y continuo.

18. Diese Verbindung von Passionsfrömmigkeit und Sterbelehre wird von der protestantischen Passionspredigt aufgenommen und als ethischer Aspekt der dogmatischen Deutung des Todes lesu integriert. Aber es ist doch unverkennbar, daß hier die Stelle ist, an der die rein gefühlsmäßige und menschliche Passionsbetrachtung ihren Ansatzpunkt finden konnte. Axmacher (1984, 202) 


\title{
Dice Descartes (Art.174) que:
}

\begin{abstract}
"la cobardía es directamente opuesta al valor, y es una languidez o frialdad que impide al alma lanzarse a la ejecución de las cosas que haría si estuviera exenta de esta pasión; y el miedo o el terror, que es contrario a la intrepidez, no es sólo una frialdad, sino también una turbación y un pasmo del alma que le quita la fuerza de resistir a los males que cree próximos" (1649, p.32) ${ }^{19}$
\end{abstract}

El filósofo racionalista afea la actitud del miedoso puesto que no conduce a nada bueno y como tales situaciones de pánico son predecibles, pueden controlarse preparándose mentalmente para el reto a afrontar. Así lo expresa en el Art. 176:

"En cuanto al miedo o el terror, no veo que pueda nunca ser loable o útil; por eso no es una pasión especial sino sólo un exceso de cobardía, de pasmo y de temor, exceso siempre vicioso, como la intrepidez es un exceso de valor que es siempre bueno, con tal de que lo sea el fin perseguido; y como la principal causa del miedo es la sorpresa, nada mejor para librarse de él que obrar con premeditación y prepararse para todos los acontecimientos cuyo temor puede causar el miedo"(1649: p.32)

Después de las dos primeras negativas de Pedro, la irrupción del coro de turba polifónico aumenta la presión sobre el discípulo que queda paralizado, incapaz de hacer frente al peligro acuciante. La tensión se libera al oír el canto del gallo, detonante que le sirve para aliviarse dando rienda suelta al llanto. Descartes (Art.132) describe físicamente la reacción de los gemidos que acompañan a las lágrimas explicando que
"los pulmones se inflan a veces de pronto por la abundancia de sangre que entra en ellos y expulsa el aire que contenían, el cual, saliendo por la garganta, produce los sollozos y los gritos que suelen acompañar a las lágrimas; y estos gritos son generalmente más agudos que los que acompañan a la risa, aunque se produzcan casi de la misma manera; esto se debe a que los órganos que sirven para dilatar o

19. Aristóteles completa la descripción cartesiana añadiendo el elemento acuciante de la inminencia del mal a percibir. La amenaza es real e inminente."Qué cosas producen miedo, a quiénes (se teme) y estando en qué disposiciones, quedará claro con lo que sigue. Admitamos, en efecto, que el miedo es un cierto pesar o turbación, nacidos de la imagen de que es inminente un mal destructivo o penoso. Porque, no todos los males producen miedo — sea, por ejemplo, el ser injusto o el ser torpe-, sino los que tienen capacidad de acarrear grandes penalidades o desastres, y ello además si no aparecen lejanos, sino próximos, de manera que estén, a punto de ocurrir. Los males demasiado lejanos no dan miedo, ciertamente: todo el mundo sabe que morirá, pero, como no es cosa próxima, nadie se preocupa”. Aristóteles (1990, p.334). 
contraer los órganos de la voz, para hacerla más gruesa o más aguda, están unidos a los que abren los orificios del corazón durante la alegría y los contraen durante la tristeza, y por tanto estos se dilatan o contraen al mismo tiempo que aquellos." (1649: p.23)

La voz del evangelista que narra el canto del gallo lo imita onomatopéyicamente: "krä-hen" (ver figura 2):

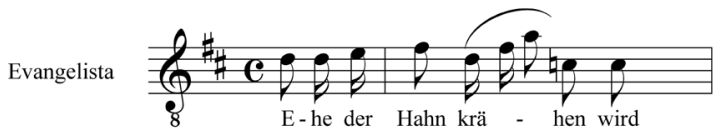

Figura 2. Recitativo 38 c de la PSM (canto del gallo).

Posteriormente mimetiza el llanto de Pedro con un melisma que calca el sonido del llanto mediante el paso cromático descendente (passus duriusculus) y un salto ascendente de séptima disminuida (saltus duriusculus) que imitaría el "grito agudo" del sollozo: "und weinetebiterlich" (ver figura 3).

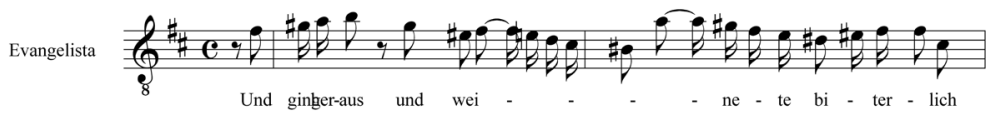

Figura 3. Recitativo 38c de la PSM (llanto de Pedro).

\section{El arrepentimiento}

La deslealtad da paso a un hondo pesar que lleva al arrepentimiento. Dice Descartes (Art.191) del arrepentimiento que "es directamente opuesto a la satisfacción de sí mismo, y es una especie de tristeza debida a que se cree haber cometido alguna mala acción; y es muy amarga, porque su causa está en nosotros;..." (1649: p.34)

Pedro sabe que ha obrado mal e implora piedad con su llanto amargo. El relato evangélico se interrumpe, con el aria llega el momento lírico por excelencia. Estas son sus palabras imaginadas poéticamente por el libretista de la PSM. 


\begin{tabular}{cc}
\hline Texto & Traducción \\
\hline Erbarme dich, Mein Gott, & ¡Ten piedad, Dios mío, \\
um meiner Zähren willen! & de mí, por mis lágrimas! \\
Schaue hier, & Mira, \\
Herz und Auge weint & mi corazón y mis ojos lloran \\
vor dir Bitterlich. & por ti amargamente. \\
\hline
\end{tabular}

Tabla 6. Aria [contralto] n'39: violín concertante, violines I/II, viola, órgano y continuo.

Bach va a sumergirnos emocionalmente en el drama, es imposible escuchar esta aria sin conmoverse, sin sentir todo el peso de la amargura de Pedro en nuestra piel. Bach es un maestro de los afectos, sabe que con ellos cautiva la atención del oyente y lo obliga a vivir el drama de la PSM en primera persona. Esta aria es un magnífico ejemplo para entender el poder que ostenta la música para trascender la palabra, creando un efecto hipnótico en el que la escucha. El hecho de que Bach no solicite aquí la voz de Pedro (bajo) para cantar su aflicción y en su lugar escoja la voz de contralto, demuestra que el aria debe interpretarse más como la expresión de un sentimiento universal (el del hondo arrepentimiento) compartible por todos los seres humanos que como una emoción particular, la de Pedro.

El aria comienza con un solo de violín introductorio de ocho compases en si menor que da paso a la voz de contralto que retoma el motivo instrumental. Durante el desarrollo vocal, instrumento y voz van alternándose con juegos imitativos. Cuando la voz no acaba la melodía, el violín acude en su ayuda para completarla. Si la voz mantiene la misma nota, el violín la adorna y complementa su honda aflicción.

A este respecto John Butt (2010) propone un ejercicio de hermenéutica musical relacionando el ritornelo del violín inimitable por la contralto con la perfección divina inalcanzable por el ser humano ${ }^{20}$. El oyente percibe la impresión de lo ideal y posiblemente llore inconscientemente su incapacidad para alcanzarlo. De ahí la honda tristeza, acrecentada por la constante intervención del violín con sus invariables ritornelos capaces de sumergir al oyente en un profundo pesar que asociado con el momento del drama produce una sensación de desamparo muy similar a la del arrepentimiento.

El texto dice: Erbarme dich, Mein Gott, um meiner Zähren willen! ... Herz. und Auge weint vor dir Bitterlich ("iTen piedad, Dios mío, de mí, por mis lágrimas! ... mi cora-

20. If the gentle deviations of 'Ich folge' suggest something of the human potential afforded by following and imitating Jesus, those of 'Erbarme dich' ('Have mercy, my God, for my tears' sake') in the Matthew Passion (39) seem to show the essential imperfection of the faithful individual together with the goal of ultimate perfection. (Butt 2010, p.79) 
zón y mis ojos lloran por ti amargamente"). La finalidad de esta aria es movernos a la piedad, para que nos apiademos del dolor de Pedro.

Dice Descartes (Art.189) que la piedad conduce al llanto:

"En esta pasión se llora muy fácilmente, debido a que el amor, enviando mucha sangre al corazón, hace que salgan muchos vapores por los ojos, y la frialdad de la tristeza, retardando la agitación de estos vapores, hace que se transformen en lágrimas...” (1649, p.34)

Diferentes madrigalismos contribuyen a representar esta pasión. El violín con su ritornelo en compás de 12/8, mimetiza un continuo fluir de lágrimas, creando una sugestión fascinante. El bajo continuo con sus pizzicatos sugiere los gemidos del dolor, la palpitación entrecortada de un corazón afligido. El intervalo inicial de $6^{\circ}$ menor imprime desde el arranque del aria una sensación de suma angustia y de debilidad. Tal y como expone Mersenne (1636) en el tercer libro de la segunda parte de su obra Harmonie Universelle dedicado a los géneros, este intervalo de $6^{\circ}$ menor "es muy adecuado para representar los grandes sufrimientos, mientras que la tercera menor representa los sufrimientos menores" (p.188) y pone como ejemplo el motete de Orlando di Lasso donde las palabras In me transierunt ("sobre mí") son expresadas por medio de la sexta menor. La razón es que "el semitono representa la debilidad ya que para entonar el tono hace falta una fuerza mayor." (p.188) ${ }^{21}$ Todos estos recursos consiguen que la música movilice nuestros "espíritus animales" en la sangre reforzando en nosotros el sentimiento de compasión por ese ser tan desvalido.

\section{La tristeza más absoluta}

Jesús ha muerto en la cruz tras sufrir penosas horas de martirio. Ahora que todo ha acabado la tristeza es devastadora, hemos perdido el ánimo. Jesús se ha sacrificado por todos nosotros, ha llevado su extremo dolor en silencio cumpliendo con el mandato divino. El texto de Picander contrapone en este arioso la figura de Adán (pecador) con la de Jesús (salvador).

21. Quant à la force et aux effets des Modes, ils dépendent particulièrement de leurs Tierces et Sextes majeures, et mineures, car les majeures sont propres pour flatter, et pour adoucir les passions, et pour exprimer la tristesse et la douleur, comme l'on voit au Motet d'Orlande, où il exprime In me transierunt par la Sexte mineure, d'où il descend après : en effet l'intervalle de cette Sexte est fort propre pour représenter les grandes douleurs, comme la Tierce mineure exprime les moindres: or elle ont cette propriété à raison du demi-ton qui représente la faiblesse, parce qu'il faut plus de force pour faire le ton. (Mersenne 1636, p. 188) 
Texto

Am Abend, da es kühle war,

Ward Adams Fallen offenbar;

Am Abend drücket inn der Heiland nieder.

Am Abend kam die Taube wieder

Und trug ein Ölblatt in dem Munde.

O schöne Zeit! O Abendstunde!

Der Friedensschluss ist nun mit Gott gemacht,

Denn Jesus hat sein Kreuz vollbracht.

Sein Leichnam kömmt zur Ruh,

Ach! liebe Seele, bitte du,

Geh, lasse dir den toten Jesum schenken,

\section{Traducción}

En el fresco de la tarde fue descubierta la caída de Adán, y en la tarde el Salvador lo castigó.

En la tarde regresó la paloma y trajo una hoja de olivo en la boca. ¡Oh bello momento, hora vespertina! La paz con Dios está ahora sellada, pues Jesús ha muerto en la cruz.

Su cuerpo llega al descanso.

¡Ay, alma querida, anda, pide que te den el cuerpo de Jesús,

¡oh don salutífero y precioso!

Tabla 7. Arioso [bajo] n64: violines I/II, viola, órgano y continuo.

En el Art. 100, explica Descartes como "en la tristeza el pulso es débil y lento, y se sienten en torno del corazón como ataduras que le aprietan y témpanos que le hielan y comunican su frialdad al resto del cuerpo..."(1649, p.18).

En el Art. 116 añade que:

"la tristeza ... contrayendo los orificios del corazón, hace que la sangre vaya más lentamente a las venas y que, tornándose más fina y más espesa, ocupe menos sitio; de suerte que, retirándose a las más anchas, que son las más próximas al corazón, abandona las más lejanas, las más visibles de las cuales son las del rostro, y esto le muestra más pálido y descarnado..." (1649, p.21).

El filósofo nos brinda una explicación mecanicista de la respuesta emocional, describiendo la lentitud de la circulación de la sangre que acaba ahogando el corazón. La música que quiere representar la tristeza plagia los movimientos de la sangre, con un movimiento lento que transmite al espíritu esa sensación de vacío provocada por la demora del movimiento. La quietud se sugiere con las largas notas mantenidas del continuo que expresan la desolación más absoluta. Este arioso comunica tristeza física y emocional sin necesidad de racionalizar nada de lo que está sucediendo en el drama. El cuerpo mimetiza la emoción sin que el cerebro intervenga en esta somatización.

Marin Mersenne (1636) en el segundo libro de los cantos de la primera parte de su obra anteriormente citada, observa que "todos los oyentes prefieren los aires tristes a los alegres, porque se acomodan mejor a la compasión que al regocijo como se ve en las tragedias y lecturas de historias tristes que arrancan las lágrimas de los ojos" (p.173) y también añade que "las tinieblas de la noche" son las más apropiadas para la "meditación de la muerte" y el "recogimiento de espíritu" 22

22. «Toutes sortes d'Auditeurs se plaisent davantage aux airs tristes, qu'aux gais, soit que les hommes 
(p.173). Es por eso quizá que el arioso se ubica en la calma del atardecer: $A m$ Abend, da es kü̈le war... O schöne Zeit! O Abendstunde!

\section{La catarsis, la purificación, la victoria de la virtud}

Superado el tiempo de la tristeza más absoluta vuelve la luz. Tras padecer el sufrimiento más hondo, el espíritu emerge purificado, renace con toda su pureza original. Interiorizamos la luz ahora eterna de Jesús que, en el texto de Picander, habitará para siempre en nuestro corazón. Esta es la función de la PSM, la catarsis tras las largas horas de angustia.

\begin{tabular}{cc}
\hline Texto & Traducción \\
\hline Mache dich, mein Herze, rein, & Purifícate, corazón mío, \\
Ich will Jesum selbst begraben. & que quiero enterrar a mi Jesús. \\
Denn er soll nunmehr in mir & Pues desde ahora en mí, \\
Für und für & y para siempre, \\
Seine süße Ruhe haben. & dulce reposo tendrá. \\
Welt, geh aus, lass Jesum ein! & ¡Mundo, apártate, deja entrar a Jesús! \\
\hline
\end{tabular}

Tabla 8. Aria [bajo] $n^{\circ}$ 65: oboes da caccia I/II, violines I/II, viola, órgano y continuo.

Bach se hace eco de la importancia de este momento sublime y hace estallar la alegría en si bemol mayor, con un compás festivo en $12 / 8$ y un ritmo trocaico, dejando atrás los oscuros momentos de dudas, de sufrimiento, de tinieblas y de culpas. La regeneración y refundación del género humano aparecen aquí como consecuencia del sacrificio. El corazón debe purificarse, dejando entrar a Jesús y al amor. Los oboes da caccia doblando a los violines aportan la energía necesaria para este saneamiento espiritual. Ha nacido un nuevo ser humano cuya máxima será seguir el ejemplo de Jesús.

Gardiner (2015,) dice de esta aria que "es en sí misma una celebración de la

se portent plus aisément à la compassion, qu'à la réjouissance, comme l'on expérimente aux tragédies, et à la lecture des élégies et des histoires tristes, qui tirent les larmes des yeux, ou qu'ils s'arrêtent plus longtemps à la considération des choses tristes, qu'à celle des joyeuses et agréables ». "... et ceux qui veulent entrer dans une profonde Méditation, choisissent les ténèbres de la nuit, et les lieux écartés, afin de n'être point troublés des bruits et des mouvements extérieurs, et d'avoir l'esprit réuni, et comme mort aux choses corporelles, pour vivre d'une vie spirituelle, animée par la contemplation de l'être éternel, dans laquelle consiste la vraie Philosophie que Platon appelle la Méditation de la mort, d'autant qu'elle nous apprend à quitter les choses muables et corruptibles, pour nous unir à l'immuable et l'immortel, qui prend son plaisir dans les âmes des vrais Philosophes. L'on peut encore prendre une autre raison du plus grand artifice, dont les Maistres se servent pour faire les chansons tristes, qui sont ordinairement plus savantes, et qui ont une plus grande multitude de beaux traits que n'ont les airs gais » Mersenne (1636, p.173, p.176). 
potencia transformadora de la música como un medio para reflexionar sobre este nuevo relato de la historia de la Pasión y extraer lecciones de él" (p. 638).

Mache dich, mein Heræe, rein..... Welt, geh aus, lass Jesum ein! ("Purifícate, corazón mío....jMundo, apártate, deja entrar a Jesús!”) Por medio de esta catarsis el oyente llega a un equilibrio final que purifica sus pasiones. Descartes habla de la virtud como un soberano remedio contra las pasiones en el Art. 148:

“...es indudable que, con tal que nuestra alma tenga en sí misma algo que la contente, ninguna contrariedad que le venga de fuera tiene poder alguno para perjudicarla; más bien sirve para aumentar su alegría, porque el ver que no pueden dañarla esas contrariedades exteriores le hace conocer su perfección. Y nuestra alma, para tener tales motivos de contento, sólo necesita seguir exactamente la virtud. Pues todo el que haya vivido de tal modo que su conciencia no pueda reprocharle que haya dejado nunca de hacer todo lo que ha juzgado lo mejor (que es lo que llamamos aquí seguir la virtud), recibe una satisfacción tan poderosa para hacerle feliz que ni los más violentos esfuerzos de las pasiones tienen jamás bastante poder para turbar la tranquilidad de su alma" (1649, p.27).

La paz de espíritu es imprescindible para llevar una vida satisfactoria, tener la conciencia tranquila, pensar haber hecho las cosas lo mejor posible. Esto es lo que el autor de las Pasiones del alma llama virtud.

Ahora bien, una vida sin placeres sería algo anodina, por eso recomienda Descartes (Art.212) al final de su tratado disfrutar de la vida manteniendo el sentido común:

"Por lo demás, el alma puede tener sus placeres aparte; más los que le son comunes con el cuerpo dependen enteramente de las pasiones: de suerte que los hombres a los que más pueden afectar son capaces de sacarle a esta vida los más dulces jugos. Verdad es que también pueden encontrar en ella la máxima amargura cuando no saben emplearlas bien y la fortuna les es contraria; más en este punto es donde tiene su principal utilidad la cordura, pues enseña a dominar de tal modo las pasiones y a manejarlas con tal destreza, que los males que causan son muy soportables, y que incluso de todos ellos puede sacarse gozo"(1649, p.37).

Las pasiones para Descartes, en contra de lo que pensaba Spinoza o Racine, son controlables. El cartesianismo forma parte de un mundo clasicista donde todavía es posible mantener el equilibrio y los valores, como se ejemplifica en las tragedias de Corneille ${ }^{23}$.

23. En la tragedia del Cid, Corneille expone un dilema moral entre el honor y el amor, en el que el protagonista se decanta por defender el honor de su padre mancillado a riesgo de perder el amor de 


\section{La conclusión}

Johann Mattheson, músico y teórico coetáneo de J.S.Bach, al hablar del oratorio en su obra Der vollkommene Capellmeister (1739) expone que en él está presente la poesía personal, mediante la introducción de personas reales que interpretan frases conmovedoras, así como hermosos pensamientos que no se muestran en una simple conversación o en una narración. Todo esto conduce las mentes a la oración y al santo temor, así como a la compasión y otras emociones, pero sobre todo a la alabanza a Dios y al gozo espiritual; a través de corales, coros, fugas, arias, recitativos con la ayuda de varios instrumentos, que acompañan de manera inteligente y modesta, según lo requieran las circunstancias ${ }^{24}$.

Esta es la idea que se tiene del oratorio en la Alemania de principios del siglo XVIII. En él todo se conforma en base a un fin: la alabanza a Dios. Para ello se utilizan todos los medios: la poesía, el canto y los instrumentos con su propia simbología. Se trata de mover las pasiones para involucrar al oyente en el drama y finalmente conducirlo al camino de la virtud que para Bach no es otro que la gloria de Dios y el gozo espiritual, entendido este en un contexto cristiano de oración y humildad.

De la capacidad de la música para mimetizar las emociones algo sabía el amigo y consejero de Descartes, Marin Mersenne que dedica amplias partes de su obra a la descripción de este fenómeno.

La técnica de persuadir mediante la manipulación de emociones se encuentra ya en Aristóteles. Al comienzo del libro II de la Retórica dice que: "las pasiones son, ciertamente, las causantes de que los hombres se hagan volubles y cambien en lo relativo a sus juicios, en cuanto que de ellas se siguen pesar y placer."(Aristóteles 1990, p.310)

Los hombres cambian sus opiniones dependiendo de las emociones que padecen. Se trata de persuadir emocionando, conmoviendo. Bach realiza la exégesis musical del texto escrito por Picander, que es a su vez una recreación poética

su amada. Ese control de las pasiones se irá diluyendo en las tragedias de Racine, donde los personajes sucumben a sus pasiones, impotentes como si de su destino se tratase.

24. In denselben werden entweder durch die Prosopopöie oder Persondichtung, da aus Dingen Personen gemacht werden, die sonst keine sind; oder ohne Verblümung, durch Einführung wircklicher Personen, solche Vorträge gethan, die nicht in einem dürren Gespräch, oder in einer Erzehlung allein, sondern in beweglichen Sätzen von allerhand Art, schöne Gedancken und Erwegungen an den Tag legen; die Gemüther sowol zur Andacht und heiliger Furcht, als auch zum Mitleiden und andern Regungen, vornehmlich aber zum Lobe Gottes und zur geistlichen Freude antreiben; durch Choräle, Chöre, Fugen, Arien, Recitative \&. die artigste Abwechselung treffen, und selbige mit verschiedenen Instrumenten, nachdem es die Umstände erfordern, klüglich und bescheidentlich begleiten. "Mattheson (1739, Teil 2 Kap 13 \$. 62) 
del evangelio. Un discurso sonoro bien ordenado con su coro inicial a modo de exordium, en el que se prepara al oyente para lo que va a escuchar y un coro final a modo de conclusión que se corresponde con la peroratio (Otterbach 2003)

La PSM se cierra con una última plegaria entonada por el coro final. Esta está precedida de un arioso, una meditación tranquila donde, tras la purificación, se alternan los solistas con el coro que representa a la comunidad dando las buenas noches a Jesús, deseándole reposo:

\begin{tabular}{|c|c|}
\hline Texto & Traducción \\
\hline $\begin{array}{l}\text { Bass: } \\
\text { Nun ist der Herr zur Ruh gebracht. }\end{array}$ & $\begin{array}{c}\text { Bajo: } \\
\text { El Señor ha sido llevado al reposo. }\end{array}$ \\
\hline $\begin{array}{c}\text { Chor: } \\
\text { Mein Jesu, gute Nacht! }\end{array}$ & $\begin{array}{l}\text { Coro: } \\
\text { ¡Mi Jesús, buenas noches! }\end{array}$ \\
\hline $\begin{array}{l}\text { Tenor: } \\
\text { Die Müh ist aus, die unsre Sünden inm } \\
\text { gemacht. }\end{array}$ & $\begin{array}{l}\text { Tenor: } \\
\text { Ha terminado la pena que nuestros pecados le } \\
\text { causaron. }\end{array}$ \\
\hline $\begin{array}{c}\text { Chor: } \\
\text { Mein Jesu, gute Nacht! }\end{array}$ & $\begin{array}{l}\text { Coro: } \\
\text { ¡Mi Jesús, buenas noches! }\end{array}$ \\
\hline $\begin{array}{c}\text { Alt: } \\
\text { O selige Gebeine, } \\
\text { Seht, wie ich euch mit Buß und Reu beweine, } \\
\text { Dass euch mein Fall in solche Not gebracht! }\end{array}$ & $\begin{array}{c}\text { Contralto: } \\
\text { Oh benditos despojos, } \\
\text { Mirad, cómo con arrepentimiento y contrición } \\
\text { os lloro, } \\
\text { pues mi pecado tal angustia os causó. }\end{array}$ \\
\hline $\begin{array}{c}\text { Chor: } \\
\text { Mein Jesu, gute Nacht! }\end{array}$ & $\begin{array}{l}\text { Coro: } \\
\text { ¡Mi Jesús, buenas noches! }\end{array}$ \\
\hline $\begin{array}{c}\text { Sopran: } \\
\text { Habt lebenslang } \\
\text { Vor euer Leiden tausend Dank, } \\
\text { Dass ihr mein Seelenheil so wert geacht' }\end{array}$ & $\begin{array}{c}\text { Soprano: } \\
\text { Os daré toda mi vida } \\
\text { por vuestro sufrimiento, infinitas gracias, } \\
\text { pues la salvación de mi alma tanto habéis } \\
\text { apreciado. }\end{array}$ \\
\hline $\begin{array}{c}\text { Chor: } \\
\text { Mein Jesu, gute Nacht! }\end{array}$ & $\begin{array}{l}\text { Coro: } \\
\text { ¡Mi Jesús, buenas noches! }\end{array}$ \\
\hline
\end{tabular}

Tabla 9. Recitativo [bajo, tenor, contralto, soprano] y coro [s, c, t, b] $n^{\circ}$ 67: flautos traversos I/II, oboes I/II, violines I/II, viola, órgano y continuo.

Acompaña a estas voces de despedida la aureola de cuerdas asociada siempre a Jesús, ahora iluminando a toda la humanidad. Las voces solistas están dispuestas ascendentemente de la más grave (bajo) a la más aguda (soprano), simbolizando un movimiento de ascensión. El bajo que había traído la calma de la hora vespertina en el arioso ${ }^{\circ} 64$, susurra ahora las palabras del reposo. El tenor, voz asociada al evangelista da por finalizado el sacrificio, la contralto retoma las palabras de arrepentimiento y contrición que ya cantó en el aria $\mathrm{n}^{\circ} 6$, y la soprano con su voz clara, asociada al alma, da las gracias por su salvación. (Cantagrel 2011, p.175) 
Tras este momento de apaciguamiento, donde la muerte se confunde con el sueño, llega el coro final con el que se cierra el drama.

\begin{tabular}{cc}
\hline Texto & Traducción \\
\hline Wir setzen uns mit Tränen nieder & Con lágrimas nos sentamos \\
Und rufen dir im Grabe zu: & y en tu tumba te decimos: \\
Ruhe sanfte, sanfte ruh! & ¡Reposa tranquilo, tranquilo reposa! \\
Ruht, ihr ausgesognen Glieder! & ¡Reposad, miembros exangües! \\
Euer Grab und Leichenstein & Vuestra tumba y lápida \\
Soll dem ängstlichen Gewissen & serán para el espíritu angustiado \\
Ein bequemes Ruhekissen & una cómoda almohada \\
Und der Seelen Ruhstatt sein. & y del alma el lugar de reposo. \\
Höchst vergnügt schlummern da die Augen ein. & Y allí con el mayor contento se cerrarán mis \\
& ojos. \\
\hline
\end{tabular}

Tabla 10. Coro final $[s, c, t, b] 68$ : flautos traversos I/II, oboes I/II, violines I/II, viola, órgano y continuo.

La comunidad en su conjunto está aquí convocada en este grandioso coro final donde se dan cita todas las voces, coros e instrumentos para finalizar la Pasión. La tonalidad escogida es la de do menor ya vinculada al descanso desde la oración en Getsemaní (el aria no 20). Esta Pasión acaba con el dulce descanso merecido por Jesús. Nos quedamos con la calma del Viernes Santo. Un coro monumental de adiós en forma da capo clausura la Pasión repitiendo una y otra vez: Rube sanfte, sanfte rub! ("Reposa tranquilo").

La PSM llega a su fin. La conciencia puede al fin descansar y cerrar los ojos sin miedo. La virtud ha prevalecido y ahora tan sólo le queda al oyente interiorizar la enseñanza evangélica.

A lo largo de este trabajo hemos intentado establecer una relación entre la musicalización de todas estas pasiones en el drama y la descripción de las pasiones expuesta por Descartes (1649) en su último libro Las Pasiones del Alma. Con esta obra el filósofo francés hace hincapié en la importancia de las pasiones en la vida de un ser humano definido por su imperfección, pero capaz de superarse, venciéndose a sí mismo para alcanzar la virtud. Esta es la enseñanza moralizadora de Descartes (no muy distinta de la moral cristiana) y su aplicación bachiana en el oratorio protestante ${ }^{25}$.

25. Butt añade que la música de Bach puede sugerir una combinación notable de los varios posibles modos de subjetividad disponibles a principios del siglo XVIII, tales como el sentido de autodescubrimiento sembrado por el humanista Montaigne o el autocontrol de las pasiones planteado por Descartes y el puritanismo pietista. "Bach's music can suggest a remarkable combination of the several potential modes of subjectivity available in the early eighteenth century, most significantly the sense of self-discovery (as seeded by Montaigne) and self-control (as seeded both by Descartes and the newer Puritan/Pietist forms of devotion).” Butt(2010,p.93) 


\section{Epílogo}

El fin de aquel mundo donde las esferas de lo privado y lo religioso se confundían estaba próximo. Explica Otterbach (2003) que esa unión hasta entonces indisoluble entre Dios y el deleite del alma habría de deshacerse a finales del Barroco. La religión iría quedando relegada a un espacio concreto, y así la música emancipada podría pasar a ser considerada un deleite en sí misma, manteniendo siempre intacto su gran poder persuasivo emocional.

Es precisamente ese atributo afectivo de la música el que permite al oyente de la tercera década del siglo XXI recibir el mensaje moral de la PSM independientemente de su adscripción religiosa. Esta Pasión transmite la idea moral de lo que está bien y lo que está mal, de la conveniencia o perjuicio de ciertos comportamientos sin necesidad de racionalizar absolutamente nada, simplemente se recibe la información de manera emocional. Es la música la que nos va persuadiendo del calado moral de las acciones, guiándonos en la tarea de transformar nuestras pasiones, de la burla a la compasión o de la venganza a la tristeza. Se vive así una experiencia moral de la que al interiorizar el relato, extraemos una enseñanza.

En esta línea un filósofo actual como Rorty apunta con mucha perspicacia que para solidarizarnos con las víctimas es mucho más efectiva la narración que la teoría, sin duda porque el grueso de la población empatiza antes con el relato que con las disquisiciones teóricas sobre la moral plasmadas en tratados filosóficos de ardua lectura ${ }^{26}$.

Tenemos, en este sentido, en el oratorio una potente arma moral que aunando relato, poesía y música, puede utilizar la persuasión emocional para crear o mantener una conciencia ética en el oyente del siglo XXI. Es el caso de la PSM que, consumida de una manera totalmente ajena al propósito religioso para el cual fue concebida, goza hoy en día de una total autonomía estética pudiendo ser escuchada en cualquier escenario imaginable y por cualquier oyente.

\section{Referencias}

Aristóteles.(1990). Retórica. Madrid: Editorial Gredos.

\footnotetext{
26. En el capítulo 4 escribe Rorty: "The language the victims once used is not working anymore, and they are suffering too much to put new words together. So the job of putting their situation into language is going to have to be done for them by somebody else. The liberal novelist, poet, or journalist is good at that. The liberal theorist usually is not" y en el ultimo capítulo insiste: "That is why I said, in Chapter 4, that detailed descriptions of particular varieties of pain and humiliation (in, e.g., novels or ethnographies), rather than philosophical or religious treatises, were the modern intellectual's principal contributions to moral progress". Rorty (1989, p.94, p.192).
} 
Epistemus - volumen 9 - número 2 (Diciembre de 2021)

DOI: https://doi.org/10.24215/18530494e031

Axmacher, E. (1984). Aus liebe will mein Heyland sterben. Hänssler-Verlag, NeuhausenStuttgart.

Bach, J.S.(1727) La Pasión según San Mateo. Recuperado de https://www.bach-cantatas. com

Bartel, D. (1997). Música Poética. Musical-Rhetorical Figures in German Baroque Music. Lincoln: University of Nebraska Press

Buelow, George J. (1973). Music, Rhetoric and the Concept of the Affections: A Selective Bibliograph, en Notes, XXX/2, pp. 250-

Butt, J. (2010). Bach's Dialogue with Modernity. Perspectives on the Passions. New York: Cambridge University Press.

Cantagrel, G. (2011). J.-S.Bach. Passions, Messes et Motets. Paris: Fayard.

Descartes, R. (1649). Las pasiones del alma. Recuperado de http://23118.psi.uba.ar/academica/carrerasdegrado/psicologia/informacion_adicional/obligatorias/034_historia_2/Archivos/Descartes_pasiones.pdf.

Descartes, R. (2001). Compendio de música. Madrid: Tecnos.Freud, S. (1982). El malestar en la cultura. Madrid: Alianza editorial.Libro de bolsillo. (Original 1930)

Gardiner, J.E. (2015).La música en el castillo del cielo. Barcelona: Acantilado.

Hill, J.W. (2008). La música barroca. Madrid: Akal.

López-Cano, R. (2020). La música cuenta. Barcelona: Esmuc.

Marissen, M. (2016). Bach \& God. Oxford: Oxford University Press.

Mattheson, J. (1739). Der vollkommene Capellmeister. Recuperado de: http://www.koelnklavier.de/quellen/matth-1739/_index.html

Mersenne, M. (1636). Harmonie universelle. Paris. Sebastien Cramoisy. Recuperado de http://www.chmtl.indiana.edu/tfm/17th/

Otterbach, F. (2003). Johann Sebastian Bach. Vida y obra. Madrid: Alianza música .

Platen, E. (2000). Johann Sebastian Bach. Die Matthäus-Passion. Kassel: Bärenreiter

Rorty, R. (1989). Contingency, irony, and solidarity. Cambridge: Cambridge University Press

Sánchez Zamorano, P. (2003).La generosidad en Las pasiones del alma de Descartes: otra lectura. En P. Sánchez [Coord.], Cuaderno gris Nro. 7, (pp. 61-84).Madrid: Universidad Autónoma. 
Schweitzer, A. (2000). J.S.Bach. El músico poeta.Buenos Aires: Ricordi americana. (original francés 1905).

Solores, I. (2020).Reflexiones en torno a la semanticidad de la música. Epistemus. Revista De Estudios En Música, Cognición Y Cultura, 8(2), p. https://doi. org/10.24215/18530494e020 